December 2010, Vol. 4(2), 43-54.

\title{
Using nutrition education and cooking classes in primary schools to encourage healthy eating
}

\author{
Claire E Drummond \\ Senior Lecturer \\ Social Health Science \\ Flinders University \\ South Australia
}

\begin{abstract}
Schools are in the unique position of being able to influence students' eating behaviours in a beneficial manner. Positive peer and teacher modelling can encourage students to try foods they exhibited distaste for previously. Pilot research has shown that when nutrition and cooking sessions are conducted in primary schools, foods refused or untried at home during meal times, such as vegetables, were asked for following the school cooking classes using that same food. In this paper I will discuss how nutrition workshops and cooking classes in primary schools can influence healthy eating habits among schoolaged children. The research indicated that there was a transfer of knowledge around healthy nutrition from a school environment to a home environment through students as agents of change.
\end{abstract}

\section{Introduction}

Schools provide the most effective and efficient way to reach a large section of the population including children, school staff and the wider community (Perez-Rodrigo and Aranceta 2001). Eating behaviour learned at school may play a significant role in ensuring that 'health-enhancing' eating behaviour is practised into adulthood (Drummond 2008). Food literacy comprises knowledge, skills and capacities to grow, select, store, prepare, cook and serve food. Within Australia, there is concern over the disappearance of cooking skills among young people (Caraher and Reynolds 2005). The lack of 'modelling' by parents preparing fresh food and the reliance on ready-prepared foods could be the reasons for this demise in cooking skills and may lead to food refusal by the child (Binnendyk and Lucyshyn 2009). Furthermore, although the consumption of food around a household table should be 
a social occasion amongst family members (Drummond and Sheppard 2007), research shows that there is a shift in conventional family mealtime activities for a variety of reasons (time constraints on the family, two parents working, after-school activities, for example). Families are now more likely to 'eat while multitasking', such as consuming food while watching television (Herbst and Stanton 2007). Food skills commonly taught in schools in the past are being phased out to make way for other disciplines and it appears that cooking skills are viewed by some as no longer necessary in a ‘hi-tech’ world (Caraher 2004).

The provision of nutrition education in the school environment may provide a positive influence on the knowledge, attitudes, skills and behaviours of young people, particularly in the improvement of student understanding about the scientific and philosophical principles of healthy eating and the development of skills needed by students to make decisions about healthy eating behaviours (O'Connor-Fleming and Parker 2001). I conducted a series of nutrition workshops with five- and sixyear-old children in three reception (pre-Year 1) classes over a period of eight weeks in 2008 in South Australia to ascertain the effects of nutrition education on primary school-aged children. In this paper I will discuss the outcomes of that research.

\section{Nutrition education in schools}

Nutrition education is an important part of the school curricula (Bullen 2004; Harvey, Spillman and Perry 1996; Nutbeam and St Leger 1997; Puts and Mattrow 2000; Ritchie 2001). Children are taught by example in conjunction with nutrition education carried out in schools. The school canteen is an important model as it either reinforces what is being taught or counteracts it (Gibbons 2001). Even as early as 1965, prior to any formalised nutrition education curriculum appearing in schools, the NHMRC stated that school canteens should facilitate nutrition education by functioning as a 'learning laboratory' to teach students about food and good eating habits (NHMRC 1988). Investigations into the benefits of school-based nutrition programs and subsequent healthy school programs shows that the academic performance and mental ability of students with good nutritional status are significantly higher than those of pupils with poor nutritional status (Haapala and Probart 2004; Jones, Kickbusch and O’Byrne 1995). It can also be argued that students who understand the benefits of a 'healthy diet' are more likely to purchase a 'healthy' alternative at the school canteen, if available (Jones et al. 1995; Robertson and Zalles 2004). Evidence suggests that, although many schools take a 'holistic' approach to health, in various cases nutrition education does not always make it into the school curriculum (Burke 2002).

The aim of school-based health promotion is threefold: to educate by providing information on nutritional needs; to empower students by increasing recognition of and ability to choose nutritious foods; and to enhance life skills by teaching simple meal preparation and introducing cooking lessons (Ritchie 2001). Caraher and colleagues (1999) contend that without these cooking skills the empowerment that health educators promote does not exist. Furthermore, not only does nutrition teaching, in conjunction with the provision of food skills in the school setting, have the capacity to empower students to make healthy individual choices, but the schools themselves can become advocates for food security and sustainability. The 
benefits of promoting healthy food choices at school may transfer to eating patterns outside of school (Bell and Swinburn 2004) and influence attitudes of the children, their parents and the wider community. The success of nutrition and cooking classes in schools can challenge the traditional model of intergenerational health so that students, rather than their parents, can be the agents of change for their family.

\section{Methodology}

In order to build knowledge, as well as developing and explaining the reasons behind children's reluctance to try different food, I used a qualitative interpretative approach in this study. It is the nature of interpretive inquiry to seek to understand a phenomenon and to interpret meaning within the social and cultural context of the natural setting (Smith 1989). I collected qualitative data from semi-structured interviews and then analysed it using thematic analysis (Patton 2002). The intent of the thematic approach was to identify and analyse patterns and regularities and progressively build up an interpretation of the field under study.

I held focus group interviews with students from the participating reception primary schools, as well as individual interviews with teachers and parents. Sixty students, three teachers and ten parents took part in the interviews. All interviews were held prior to the commencement of the workshops as well as at the completion of the eight-week sessions. Recent research has indicated that data collected from children within this age group provides adequate depth and knowledge of the issues discussed within focus group interviews and therefore yields rich, useable information (Drummond, Drummond and Birbeck 2009). Detailed information forms were sent to each participant and consent forms were signed prior to the interviews. Parental consent was also obtained from the students' parents prior to the research. Ethics approval was obtained from Flinders University and the Department of Education and Children's Services (DECS). I liaised with the principal and teachers within the schools to ensure that the interviews did not disadvantage the students and their regular classroom learning.

\section{Nutrition workshops}

Sixty students from three reception classes participated in the eight-week nutrition program. All students participated in the weekly nutrition workshops that were one hour in duration and incorporated nutrition education, and producing and cooking various items of food. The main aim of the workshops was to introduce the Australian Guide to Healthy Eating (Smith, Kellett and Schmerlaib 1998) to the students and familiarise the students with the preparation and cooking of foods from the healthy eating guide. While in the company of their peers, the students were asked to help prepare and try food for which they had previously verbalised distaste. Table 1 depicts the weekly topics introduced to the school students and the corresponding cooking class. 
Table 1: Weekly nutrition and cooking workshops

Week Topic

Week one:

Food glorious food

Week three:

Orange and lemon squeezing

Week four:

Carbohydrates

Week five:

Protein

Week six:

Make your snack

Week seven:

Fluids

Week eight:

Recap!
Introduction to the healthy food pizza, the 'Australian

Guide to Healthy Eating' poster and how it relates to a pizza shape.

Students will make a 'healthy pizza'.

Children will be taught about the five food groups.

To promote fruit and vegetable consumption the students will help make a fruit and vegetable man. They will be encouraged to touch, taste and smell the fruits and vegetables as he comes together.

Discussion with students on how the fruit and vegetables help us to be healthy, give energy to run and play. Make coco-bananas to try.

To help students distinguish between different tastes (sweet and sour) and to introduce taste buds.

Students will try different tastes and to label on a tongue worksheet where they thought they tasted them.

What are carbohydrates and why are they so important to our bodies?

The students will investigate the different foods that contain carbohydrates.

Students will make fresh pasta.

What is protein and where is it found? Why are they so important to our bodies?

The students will investigate the different foods that contain protein.

Students will taste test foods containing protein and make scrambled eggs.

Introduce students to making and choosing a 'healthy' snack.

Why are fluids (especially water) so important to us? Students will use different products with fruit to make different fruit drinks.

A look back at the workshops and reintroduce the Australian Guide to Healthy Eating as well as put together a recipe book of the foods we made and tasted. 
Each week the students were exposed to nutrition education, followed closely by 'hands on' food preparation and cooking. Strict hygiene practices were followed as per the Australian Food Safety Practices and General Requirements (Australia New Zealand Food Authority 2001) and the researcher was informed of any student who had a food allergy. Once the food was prepared and/or cooked, all students were invited to taste it.

\section{Results and discussion}

The verbal feedback from the parents of the children participating in the workshops identified that foods previously not tried or refused at home were now being asked for at meal times. Parents claimed that their children were willing to help prepare the food and also encouraged their siblings to join in. Five major themes were presented prior to the workshops, while seven were identified post-workshop. Table 2 indicates the major themes arising from the thematic analysis.

Table 2: Themes identified by participants

Students' themes Parents' themes Teachers' themes

Prior to workshops

Perceptions of health Difficulties in introducing Nutrition education different food

Time constraints Time constraints

\section{Post-workshops}

This is yummy!

Food at home

Positive peer pressure
How can we make this at Fruit time home?

Breakfast concerns
Vegetable gardens

The foods introduced in weeks one, two, four and five generated the most comments as they were typically untried or less likely to be cooked at home due to children's resistance in consuming them. This was particularly relevant in week one's 'healthy eating pizza' and week two's 'fruit and vegetable man'. Both of these weeks saw the students using fresh fruit and vegetables in an inventive way to encourage consumption.

I discussed the term 'health' with the participants prior to the workshops to determine their understanding of what 'health' meant to them. All of the participants had differing perceptions of the term although it was the students who gave the broadest range of interpretations. The majority of students cited 'fruit and 
vegetables' when asked to define the term 'healthy'. When prompted, the students also included 'exercise and sport' within their definition. Other definitions of health cited by the students included:

- 'keeping fit'

- 'drinking milk and water'

- 'watching sport on TV'

- ' 'riding a bike outside'

- ' 'eating a variety of healthy foods'

- $\quad$ eating 'carrots for your eyes'.

Students also clarified their perception of health with examples. One group of students provided this discourse on this issue:

Q: What is your idea of health? Please go around the group.

A1: OK, umm, eats lots of vegetables and eat healthy, exercise and just be healthy.

A2: Look after your body, drink lots of water, and vegetables and bread and all that.

A3: I reckon healthy is like you need to drink lots of water, take your dogs for walks so you dogs get exercise and they're healthy as well and stuff like that.

A4: Well, healthy would be to me, would be to exercise and to have plenty of vegetables and fruit and eat, have your serves of meat so you get the protein.

A3: I don't think you should eat too much of the stuff that you should eat because otherwise you will get fat.

A5: Well, my idea of healthy would be to drink lots of water, around about two litres a day.

A6: I think you should eat lots of fruit and vegetables and keep yourself hygienic.

This dialogue was representative of other students in the research and is consistent with findings from Drummond et al.'s (2009) research on primary school-aged children's understanding of nutrition. Conversely, when asked what 'healthy choices' students ate at home, fruit and vegetables were not the main foods 
mentioned. Items such as 'chocolate', 'fried chicken because chicken is good for you', and 'chips because they are made from potatoes' were three food items that were referred to on a number of occasions by different students. Current research by Koh and colleagues (2010) found that children as young as six months of age are being fed foods such as hot chips and take away foods. It is not surprising then that primary school-aged children also list these types of food among their favourites.

Although apples and carrots were mentioned as 'healthy' by students, very few other fruits and vegetables were mentioned by students for consumption at home. These statements support the recognised fact that Australian children do not consume enough fruit and vegetables. The complexities in fruit and vegetable consumption in schools is supported by the 2007 Australian National Children's Nutrition and Physical Activity survey's main findings (Department of Health and Ageing 2007), which indicated that a large proportion of children did not meet the daily recommended serves of fruits and vegetable intake in line with the Dietary Guidelines for Children and Adolescents (NHMRC 2003). Noteworthy, two of the post-workshop themes raised by children: 'this is yummy' and 'food at home' were in direct contrast to many comments raised about health previously. Students altered their view on what they would like to eat at home. Parents' comments were congruent with the students', with many asking for recipes so that they could 'make the foods at home just like at school'. Parents also commented on the difficulty of introducing certain foods (interestingly, the food cited as one of the most difficult was eggs) in the past; however since trying the foods at school with the 'other children' their children were asking for it at home. The students also alluded to positive peer pressure, with many commenting, 'the rest of the class was eating it and I didn't want to be left out'.

The theme overwhelmingly raised by the parents was the issue of 'time constraints'. Parents referred to being 'time poor' and, while expressing that they would like to allow their children to cook with them, many wanted to prepare the night's dinner as 'quickly as possible' so that they were able to 'feed hungry children'. Moreover, the majority of families did not eat together as a family unit and instead had two separate meal times: one for the children and one for the parents. Mostly this was due to one parent arriving home late from work. Parents and children not eating together raises some social issues. The consumption of food can be seen as a social occasion where family members gather to eat and communicate. Meal times provide the possibility for sharing and bonding within a pleasant atmosphere (Ikeda 2004) and when families no longer eat together they may miss this opportunity. Furthermore, many of the children in this study did not regularly use a knife and fork, instead using their hands to eat (for foods such as nuggets and chips) or a spoon (for foods such as pasta). The correct use of a knife and fork can assist a child with their development of fine motor skills required for actions such as holding a pen or tying shoelaces. When a child feels comfortable using eating utensils such as a knife they are also more likely to attempt a variety of different foods.

The teachers in this study claimed that they would like to introduce more cooking and tasting workshops in their classes if they had the time. Rationalisation surrounding the 'success' of the introduction of foods previously untried or 
'disliked' by the students fuelled the teachers' claims. It has been recognised that providing nutrition education in the school environment provides a positive influence on the knowledge, skills and behaviours of young people, particularly in the improvement of student understanding around the scientific and philosophical principles of health eating and the development of skills required by students to make decisions about healthy eating behaviours (O’Connor-Fleming and Parker 2001). Due to the success of the workshops, all of the participating schoolteachers introduced a 'fruity Friday' initiative whereby the students bought fruit to school; it was cut up the teachers and then shared amongst the class. Accompanying initiatives adopted by the classes due to these workshops were: ongoing cooking workshops utilising a similar program to that introduced; nutrition information nights provided to the school community on issues such as 'breakfast importance' and 'healthy lunchbox ideas'; planning a vegetable garden in an unused plot of land within the school - this initiative was proposed by the teachers from the classes to the rest of the school community and was slowly being established. Posters to support healthy eating were also developed and displayed around the school.

This research on nutrition and cooking classes indicates that children are engaged and interested in cooking and nutrition. This is important and could help inform the implementation of cooking programs in school. While Caraher (2004) contends that food skills commonly taught in schools in the past are being phased out, this study indicates that not only do students want to cook, they changed their eating habits to incorporate new foods. Students who had previously never worked with raw food material (i.e. eggs, flour) were learning how to crack eggs, stir food and use cooking utensils such as knives. It has been well established that dietary behaviour and its predicators are intergenerationally related (i.e. adults' knowledge about health is a significant predicator of their child's knowledge about health) (Lorenzo et al. 1998; Rimal 2010); however this research also indicates that children can be the agents of change and influence healthy eating within their family.

\section{Summary of results}

- Positive peer pressure occurred with the students, with many remarking 'the rest of the class was eating it and I didn't want to be left out'.

- The teachers in this study claimed that they would like to introduce more cooking and tasting workshops in their classes if they had time.

- Children not only wanted to cook at home; they changed their eating habits to incorporate new foods although this only lasted if the parents supported the new food intake at home.

- Parents were more likely to try to eat together as a family unit so as to encourage a social and talkative atmosphere with their children; however this was only in some instances when the whole family was available at meal time.

- The children developed skills in the selection, storage, preparation, cooking and serving of healthy food. 
- Families changed their mealtime behaviour to incorporate the consumption of student- and parent-prepared meals.

- Overall, the workshop findings showed a marked improvement in nutrition choices, with participants consuming healthier food over the course of the eight-week workshops.

\section{Conclusion}

Nutrition education is an important part of the school curricula. Children are taught by example in conjunction with nutrition education. The provision of nutrition education in the school environment provides a positive influence on the knowledge, attitudes, skills and behaviours of young people. This research identified that foods previously not tried or refused at home were now being asked for at meal times. Furthermore, parents claimed that children were more willing to assist in food preparation at home and also encouraged their siblings to join in.

Students increased their understanding of the scientific and philosophical principles of healthy eating and developed skills to make decisions about healthy eating behaviours. Children considered that things allowed at school are healthy, further supporting the benefits of using the school environment to promote healthy eating choices and influence behaviour. Moreover, there were expectations from parents that the school environment should present sound examples of healthy eating messages and provide opportunity through education, policy and practice. Nutrition teaching, in conjunction with the provision of food skills in the school setting, has the capacity not only to empower students to make healthy individual choices, but the schools themselves can become advocates for food security and sustainability.

Due to the positive outcomes from the pilot research, further research with a larger number of schools is warranted to ascertain if these results are transferable in other schools and to inform education policy within primary schools on the importance of incorporating nutrition lessons into the school curriculum.

\section{References}

Australia New Zealand Food Authority 2001, Standard 3.2.2 food safety practices and general requirements, Australia New Zealand Food Authority, Canberra.

Bell, AC and Swinburn, BA 2004, 'What are the key food groups to target for preventing obesity and improving nutrition in schools?' European Journal of Clinical Nutrition, vol. 58, no. 2, pp. 258-263.

Binnendyk, L and Lucyshyn, JM 2009, 'A family-centered positive behaviour support approach to the amelioration of food refusal behavior: an empirical case study', Journal of Positive Behavior Interventions, vol. 11, no. 1, pp. 47-62. 
Bullen, K 2004, 'Changing children's food and health concepts: a challenge for nutrition education', Education \& Health, vol. 22, no. 4, pp. 51-55.

Burke, L 2002, 'Healthy eating in the school environment: a holistic approach', International Journal of Consumer Studies, vol. 26, no. 2, pp. 159-163.

Caraher, M 2004, 'Children's views of cooking and food preparation', British Food Journal, vol. 106, no. 4, pp. 255-273.

Caraher, M, Dixon, P, Lang, T and Carr-Hill, R 1999, 'The state of cooking in England: the relationship of cooking skills to food choice', British Food Journal, vol. 101, no. 8, pp. 590-609.

Caraher, M and Reynolds, J 2005, 'Lessons for home economics pedagogy and practice', Journal for the Home Economics Institute of Australia, vol. 12, no. 2, pp. 2-3.

Department of Health and Ageing 2007, 2007 Australian National Children's Nutrition and Physical Activity Survey: main findings, Commonwealth of Australia, Canberra.

Drummond, CE 2008, The role and function of the school food service and its position within the school system, $\mathrm{PhD}$ thesis, University of South Australia, Adelaide.

Drummond, C and Sheppard, L 2007, 'Similarities and differences between aged care facilities and school food services', Diversity in Health and Social Care, vol. 3, pp. 261-268.

Drummond, M, Drummond, C and Birbeck, D 2009, 'Listening to children’s voices in qualitative health research', Journal of Student Wellbeing, vol. 3, no. 1, pp. $1-13$.

Gibbons, K 2001, 'And then to school: what about nutrition?' Health Education Australia, vo. 1, no. 2, pp. 22-25.

Haapala, I and Probart, C 2004, 'Food safety knowledge, perceptions, and behaviors among middle school students', Journal of Nutrition Education \& Behavior, vol. 36, no. 2, pp. 71-76.

Harvey, PWJ, Spillman, DA and Perry, CL 1996, 'Stakeholder participation in the development of a nutrition education program in an Australian secondary school', Health Promotion Journal of Australia, vol. 6, no. 3, pp. 21-27.

Herbst, KC and Stanton, JL 2007, 'Changes in family dynamics predict purchase and consumption’, British Food Journal, vol. 109, no. 8, pp. 648-655. 
Ikeda, J 2004, 'Culture, food, and nutrition in increasingly culturally diverse societies' in A sociology of food and nutrition: the social appetite, ed. J Germov and L Williams, Oxford University Press, South Melbourne, pp. 288-313.

Jones, J, Kickbusch, I and O’Byrne, D 1995, 'Improving health through schools', World Health, vol. 48, no. 2, pp. 10-12.

Koh, GA, Scott, JA, Oddy, WH, Graham, KI and Binns, CW 2010, 'Exposure of non-core foods and beverages in the first year of life: results from a cohort study', Nutrition and Dietetics, vol. 67, pp. 137-142.

Lorenzo, T, Stucky-Robb, R, Vander Wal, J and Gotham, H 1998, 'Determinants of exercise among children: II. A longitudinal analysis’, Preventative Medicine, vol. 27, pp. 470-477.

NHMRC 1988, Nutrition education in schools, National Health and Medical Research Council, Canberra.

NHMRC 2003, Dietary guidelines for children and adolescents in Australia, National Health and Medical Research Council, Canberra.

Nutbeam, D and St Leger, L 1997, Priorities for research into health-promoting schools in Australia, Australian Health Promoting Schools Association, Sydney.

O’Connor-Fleming, ML and Parker, E 2001, Health promotion: principles and practice in the Australian context, 2nd ed., Allen \& Unwin, Sydney.

Patton, MQ 2002, Qualitative research and evaluation methods, 3rd ed., Sage, California.

Perez-Rodrigo, C and Aranceta, J 2001, 'School-based nutrition education: lessons learned and new perspectives', Public Health Nutrition, vol. 4, no. 1A, pp. 131-139.

Puts, K and Mattrow, J 2000, 'Healthy primary school canteens', Australian Journal of Primary Health Interchange, vol. 6, no. 1, pp. 111-120.

Rimal, RN 2010, 'Intergenerational transmission of health: the role of intrapersonal, interpersonal, and communicative factors', Health Education and Behavior, vol. 30, no. 1, pp. 10-28.

Ritchie, A 2001, 'Nutrition education and promotion in primary schools', Australian Journal of Holistic Nursing, vol. 8, no. 2, pp. 39-44. 
Robertson, TP and Zalles, D 2004, 'Nutrition education program Nutrition Pathfinders teaches children how to make healthful food choices', Journal of Nutrition Education Behaviour, vol. 37, pp. 41-42.

Smith, A, Kellett, E and Schmerlaib, Y 1998, The Australian guide to healthy eating: background information for nutrition educators, Commonwealth of Australia, Canberra.

Smith, JK 1989, The nature of social and educational inquiry: empiricism versus interpretation, Ablex Publishing Corporation, Norwood, NJ. 